\title{
Effects of Large Retarder Overdose on Concrete Strength Development
}

\author{
W.P.S. Dias, M.A.N. Dewapriya, E.A.C.K. Edirisooriya and C.G. Jayathunga
}

\begin{abstract}
Retarders are used to delay the setting time of concrete. Retarder overdosing is not an uncommon problem, but its effects are not well understood. In this study, laboratory tests were conducted to determine the effect of retarder overdosing on the setting time and strength of concrete, using both cubes, and cores from a large specimen. It was found that overdose levels of 3 times the normal dosage had little effect on setting and strength development. Also, concrete with even 6 times the normal dosage of retarder did eventually set and gain strength. Tests were also conducted to determine cement setting time under different temperature and surface drying (wind) conditions, in order to make inferences regarding strength development of concrete surfaces compared to interiors.
\end{abstract}

Keywords: Retarder overdose, setting time, strength development, surface vs. interior

\section{Introduction and Objectives}

A large number of retarding admixture products are available in the market. Some of their desirable effects are described by the manufacturers, but there is no information on some other effects, such as the effect of overdosing, with no allowable over dosage limit being specified. Such overdosing can occur in practice due to faults in a retarder dispenser at a batching plant. There is also not much research literature on large overdosing of retarder admixtures. In this paper we review some of the existing knowledge regarding the effects of retarder overdosing on concrete strength development and setting time, and present the results of testing designed to achieve the following research objectives.

(i) To find the setting times, and strength development with age, and depth of thick concrete sections, for concretes cast with multiples of normal retarder dosage.

(ii) To make inferences about the quality of the surface and interior of a thick concrete section by studying the effect of wind and temperature on cement setting time.

\section{Review of Existing Knowledge}

There are three types of retarding admixtures recognized by ASTM C494-1988 [1]. Type B simply retards the hydration of Portland cement. Type D not only retards the hydration but also acts to disperse the cement particles and thereby provides water reduction. Type $G$ is a high range water reducing and set retarding admixture. The most commonly used chemical retarder is the Type $\mathrm{D}$ variety and is referred to as a water reducing and retarding admixture. The active ingredient, usually organic in nature, is absorbed on the surface of cement particles and also imparts like and repelling charges to the surfaces. The shielding of the cement particles reduces their reactions with water and causes retardation; the repelling charges disperse the cement particles and enable water reduction [2].

Dodson [2] has pointed out that the presence of set retarding admixtures causes an increase in 28 day strength over a reference where no retarder is added. He used different quantities

Eng (Prof) W.P.S. Dias, PhD(Lond), DIC, CEng, FIE(Sri Lanka), MIStructE, Senior Professor of Civil Engineering, University of Moratuwa;

M.A.N. Dewapriya, BScEng(Hons);

E.A.C.K. Edirisooriya, BScEng(Hons); and

C.G. Jayathunga, BScEng(Hons) 
of Type D retarding admixtures up to $0.18 \%$ (solids by weight of cement), and found that strength and final setting time increased by up to $35 \%$ and $300 \mathrm{~min}$. respectively. It appears that the slower formation of the concrete hydration products - due to the presence of the set retarding admixture - is responsible for the higher later strengths. As a result of using set retarding admixtures (Type B or D), the normal hydration processes are slowed down so that the very early strengths (e.g. 1 day) are lower. At the same time, the slower rates of formation of the hydration products give them a greater opportunity to align or organize themselves in the cement matrix and produce higher later strengths [2].

Ramachandran [3] has shown that in the presence of retarders, the early strengths of cement mortar are lower than that of the reference specimen with no retarder. The 1 day compressive strength reduced from $11.8 \mathrm{MPa}$ down to $1.2 \mathrm{MPa}$ at an addition rate of $2 \%$ of a phosphoric acid retarder. The 28 day strength increased from $45 \mathrm{MPa}$ to $65 \mathrm{MPa}$ for a $1 \%$ dosage but was $60 \mathrm{MPa}$ at a $2 \%$ dosage.

Two cases of large retarder overdosing in practice have been investigated by the first author. In the first one, setting was delayed by 3 days. The 5 day strength of cubes cast at the factory from the delivered concrete gave an average cube strength of $22.8 \mathrm{MPa}$ for a grade 25 concrete. The estimated equivalent potential cube strengths of cores extracted at the ages of 16 and 29 days were $26 \mathrm{MPa}$ and $28 \mathrm{MPa}$ respectively [4].

Another grade 25 concrete in a transfer slab took 10 days to set due to a retarder overdose of around 4 times the normal dosage. Cores extracted after 53 days yielded an estimated equivalent potential cube strength of $32 \mathrm{MPa}$ and no significant difference was found between the concrete that had set normally and with delay [5].

Setting times of Portland cement paste containing 3 types of retarders with different dosages have been found to increase with increasing dosages; the gaps between initial and final setting times also increased [3].

\section{Materials and Methods}

\subsection{Materials}

A commonly used brand of Portland limestone cement was used for the tests. The coarse aggregate size was $20 \mathrm{~mm}$. Grading of both coarse and fine aggregates conformed to the limits specified in BS 882:1992 [6]. Pozzolith $300 \mathrm{R}$ was used as the set retarding admixture. The trade literature indicates that it has been formulated to meet the requirements of ASTM C494-1988 [1] for Type B and D admixtures and is a very commonly used retarder. The range of recommended dosages is 2 to $3.5 \mathrm{ml} / \mathrm{kg}$ of cement.

A well established mix for grade 25 concrete was used for the research. The target mean cube strength was $35 \mathrm{MPa}$ at 28 days. The proportions, which have accounted for the water reduction due to the presence of the retarder, are as follows: cement $-331 \mathrm{~kg} / \mathrm{m}^{3}$, water $-195 \mathrm{~kg} / \mathrm{m}^{3}$, fine aggregate $-768 \mathrm{~kg} / \mathrm{m}^{3}$, coarse aggregate $-1106 \mathrm{~kg} / \mathrm{m}^{3}$, Pozzolith 300R - $993 \mathrm{ml} / \mathrm{m}^{3}$ (i.e. $3 \mathrm{ml} / \mathrm{kg}$ of cement, and towards the upper end of the recommended dosage range).

\subsection{Tests on concretes}

Castings were done for four different retarder dosages, namely a normal dosage of $3 \mathrm{ml} / \mathrm{kg}$ cement (designated "ND"), and 3, 4.5 and 6 times the normal dosage, designated "3ND", "4.5ND" and "6ND" respectively. The total volume of the casting was $0.18 \mathrm{~m}^{3}$. The concrete was used to fill $150 \mathrm{~mm}$ cubes, setting time containers and a large specimen of dimensions $0.75 \mathrm{~m} \times 0.36 \mathrm{~m} \times 0.39 \mathrm{~m}$, the last dimension being the depth. The test programme allowed for 2 specimens per condition for cores and 3 specimens per condition for cubes; in some cases the latter was also reduced to 2, when testing durations had to be extended. Replication was very good in all cases. 
A slump test was done for each casting. The concrete setting time tests were carried out according to ASTM C403-1986 [7] for each dosage and were repeated in order to obtain a replicate of the results.

Both the cubes and the large specimens were cured to simulate site conditions. Curing under damp hessian was carried out for 7 days, with specimens being in their moulds. At 7 days the cubes were demoulded. Strength testing of cubes and extraction of $75 \mathrm{~mm}$ dia. cores from the large specimens were planned for ages of 7 , 14 and 28 days, but longer durations too had to be resorted to at higher overdosing levels. In fact, it was possible to extract the first set of cores from the $4.5 \mathrm{ND}$ specimen only after 49 days and from 6ND specimen after 119 days. The vertically drilled cores were sliced in order to take three $85 \mathrm{~mm}$ height core samples from the top, middle and bottom of the large (390 $\mathrm{mm}$ deep) specimen. Care was taken to discard the top $40 \mathrm{~mm}$ and bottom $25 \mathrm{~mm}$ from the long cores. Rebound hammer testing was also carried out on the large specimen with a vertically downward hammer orientation just before cores were extracted; this is because rebound hammer testing is often used in practice to ascertain the extent to which the concrete has hardened, in situations of delayed setting.

\subsection{Cement setting time tests}

The cement setting time test was carried out according to BS 4550: Part 3: 1978 [8]. The water/cement ratio required to give a paste of standard consistence was 0.3. Control specimen moulds were kept at the room temperature of around $31^{\circ} \mathrm{C}$ and $85 \% \mathrm{RH}$. Other specimen moulds were kept in an oven at a temperature of $53^{\circ} \mathrm{C}$ and sealed by placing a circular rubber ring on the circumference of the mould with a heavy steel plate on top of it. The purpose of sealing was to prevent moisture escaping from the cement paste, thus simulating the sealed condition in the interior of a thick concrete element. Yet other specimens were kept at $31^{\circ} \mathrm{C}$ but under a wind speed of $2.5 \mathrm{~m} / \mathrm{s}$, generated by an electric fan. The above tests were done with and without retarder (at the normal dosage) and repeated in order to obtain replicates of the results; replication was very good.

\section{Results and Discussion}

\subsection{Slump variation}

Table 1 indicates the variation of slump with retarder dosage. It should be noted that the standard mix design accounted for the water reducing property of the retarder. However, no additional water reduction was made at higher dosages of the retarder. Especially in this context, although higher slump was expected at higher dosages, Table 1 indicates that the reverse was true. More experimentation is probably called for, prior to making definite conclusions.

Table 1 - Variation of slump with retarder dosage

\begin{tabular}{cc} 
Dosage (x ND) & Slump (mm) \\
\hline 1.0 & 210 \\
3.0 & 190 \\
4.5 & 190 \\
6.0 & 175 \\
\hline
\end{tabular}

\subsection{Concrete setting time}

The initial and final setting time results are shown in Table 2, together with the variation from the mean. The setting times for all retarder overdosed mixes are significantly greater than for the concrete mixes with the normal dosage of retarder. In addition, there appears to be considerable variability between replicates at a dosage of $6 \mathrm{ND}$.

Table 2 - Variation of concrete setting time with retarder dosage

\begin{tabular}{|c|c|c|c|c|c|c|}
\hline \multirow{3}{*}{$\begin{array}{l}\text { Dosage } \\
\text { (xnd) }\end{array}$} & \multicolumn{6}{|c|}{ Setting time $(\mathrm{h})$} \\
\hline & \multicolumn{3}{|c|}{ Initial } & \multicolumn{3}{|c|}{ Final } \\
\hline & Trial 1 & Trial 2 & Variation & Trial 1 & Trial 2 & Variation \\
\hline 1.0 & 11.1 & 9.1 & $(+/-10 \%)$ & 12.2 & - & \\
\hline 3.0 & 39.4 & 42.4 & $(+/-4 \%)$ & 42.7 & 52.3 & $(+/-10 \%)$ \\
\hline 4.5 & 32.7 & 44.1 & $(+/-15 \%)$ & 60.8 & 54.5 & $(+/-5 \%)$ \\
\hline 6.0 & 31.9 & 80.8 & $(+/-43 \%)$ & 55.1 & - & \\
\hline
\end{tabular}




\subsection{Concrete cube strength development}

Concrete cube strength development with age for different retarder dosages is shown in Table 3. Cubes with a normal retarder dosage have recorded the highest compressive strength at 28 days. The strength development of the concrete with a retarder dosage of $3 \mathrm{ND}$ is also only a little below that of the concrete with a normal retarder dosage. However there is a significant delay in strength gain at retarder dosages of 4.5ND and 6ND. Such delays would not be acceptable in concrete practice. Nevertheless, even at these high dosages the concrete does in fact gain in strength. Both the 98 day strength of the concrete with a retarder dosage of $4.5 \mathrm{ND}$ and the 119 day strength of the concrete with a retarder dosage of $6 \mathrm{ND}$ were greater than the 28 day strength of the normally dosed concrete. The fact that concretes with retarder overdosing do ultimately gain their strengths is in agreement with the literature $[2,3]$. This should not however be a license to concrete producers to be slack in quality control.

Table 3 - Average cube strength at different ages and retarder dosages

\begin{tabular}{ccccc}
\hline & \multicolumn{4}{c}{$\begin{array}{c}\text { Average cube strength }(\mathrm{MPa}) \text { for } \\
\text { dosages of }\end{array}$} \\
\cline { 2 - 5 } $\begin{array}{c}\text { Age } \\
\text { (days) }\end{array}$ & ND & 3ND & $4.5 \mathrm{ND}$ & $6 \mathrm{ND}$ \\
\hline 7 & 29 & 22 & 2 & 2 \\
14 & 34 & 27 & 2 & 2 \\
28 & 35 & 32 & 7 & 2 \\
49 & - & - & 25 & - \\
98 & - & - & 39 & -
\end{tabular}

\subsection{Concrete core strength development}

Table 4 shows strength development (in terms of equivalent in-situ cube strength) with depth and time for the concretes tested. In all cases, top cores have recorded the lowest strength and in almost all cases the bottom cores the highest. Even where the bottom core strengths are not the highest, they are only marginally lower than the middle core strengths. This variation in strength is well documented and is due to better compaction of the concrete bottom layers and to bleeding and greater air contents in the top layers.

Table 5 shows the ratios between the bottom core equivalent in-situ cube strengths and corresponding test cube strengths for all the concretes tested. This is depicted graphically in Figure 1 too.

Table 5 and Figure 1 clearly show that (bottom) cores have recorded lower strengths compared to cubes at higher retarder dosages, although there appears to be a maximum in the ratio at a dosage of 3ND. Once again there is a difference between the behaviour of concretes with retarder dosages of ND and 3ND the one hand, and those with dosages of 4.5ND and 6ND on the other.

Table 4 - Variation of core strength with age, dosage and depth

Table 5 - Ratios of bottom core equivalent in-situ

\begin{tabular}{|c|c|c|c|c|c|c|c|c|c|}
\hline \multirow{3}{*}{$\begin{array}{l}\begin{array}{l}\text { Age } \\
\text { (days) }\end{array} \\
\text { Dosage }\end{array}$} & \multicolumn{9}{|c|}{ Equivalent in-situ cube strength (MPa) } \\
\hline & \multicolumn{2}{|c|}{7} & \multicolumn{2}{|c|}{14} & \multicolumn{2}{|c|}{28} & \multirow{2}{*}{$\begin{array}{c}49 \\
4.5 \mathrm{ND}\end{array}$} & \multirow{2}{*}{$\begin{array}{c}98 \\
4.5 \mathrm{ND}\end{array}$} & \multirow{2}{*}{$\begin{array}{c}119 \\
6 \mathrm{ND}\end{array}$} \\
\hline & ND & 3ND & ND & 3ND & ND & 3ND & & & \\
\hline Top & 20.3 & 19.5 & 22.8 & 23.7 & 24.2 & 27.7 & 16.9 & 20.7 & 17.8 \\
\hline Middle & 25.1 & 20.3 & 23.5 & 25.9 & 25.1 & 28.1 & 17.1 & 24.7 & 17.4 \\
\hline Bottom & 25.9 & 25.2 & 27.1 & 25.4 & 30.0 & 29.6 & 17.3 & 24.6 & 23.6 \\
\hline & & & & & & ge & Bottom col & quivalent & itu \\
\hline
\end{tabular}




\begin{tabular}{ccccc}
\hline (days) & \multicolumn{4}{c}{ cube strength/Test cube strength } \\
\cline { 2 - 5 } & ND & 3ND & $4.5 \mathrm{ND}$ & 6ND \\
\hline 7 & 0.89 & 1.15 & - & - \\
14 & 0.79 & 0.94 & - & - \\
28 & 0.86 & 0.93 & - & - \\
49 & - & - & 0.69 & - \\
98 & - & - & 0.63 & - \\
119 & - & - & - & 0.64 \\
\hline
\end{tabular}

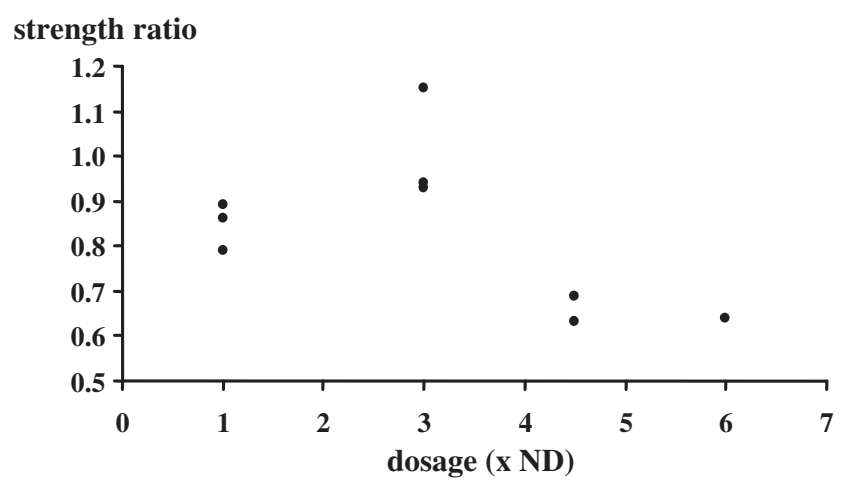

Figure 1 - Ratios of bottom core equivalent in-situ cube strength to test cube strength for different dosages

\subsection{Rebound hammer tests on large specimens}

The rebound hammer results were adjusted for the vertically downward orientation of the hammer and converted to estimated cube strength values, using a correlation that had been previously developed [9]. Table 6 shows the ratios between the strengths thus obtained and the equivalent cube strengths corresponding to the top cores for concretes with the two smaller retarder dosages at different ages.

The ratios for the normally dosed concrete are much higher than for the concrete with a retarder dosage of 3ND at all three ages. Also, all the ratios in the former case are greater than unity, and in the latter case less than unity. This suggests that the surfaces of overdosed concretes are weaker than the actual subsurface strength. Surfaces were so weak in concretes with larger retarder dosages that it was not possible to take rebound hammer readings up to 28 days for the $4.5 \mathrm{ND}$ case and even after 98 days for the 6ND one.
Table 6 - Ratios of "rebound strength" to top core strength

\begin{tabular}{ccc}
\hline \multirow{2}{*}{$\begin{array}{c}\text { Age } \\
\text { (days) }\end{array}$} & "Rebound strength" / Top core strength \\
\cline { 2 - 3 } & ND & 3ND \\
\hline 7 & 1.25 & 0.80 \\
14 & 1.23 & 0.78 \\
28 & 1.44 & 0.91 \\
\hline
\end{tabular}

\subsection{Cement setting time}

The cement setting time results are indicated in Table 7 for specimens with and without the normal retarder dosage.

Table 7 - Cement setting time results

\begin{tabular}{llcc}
\hline & & $\begin{array}{c}\text { With } \\
\text { retarder }\end{array}$ & $\begin{array}{c}\text { Without } \\
\text { retarder }\end{array}$ \\
\hline $\begin{array}{l}\text { Control } \\
\text { specimen } \\
\text { (at 31 C })\end{array}$ & Initial (h: min) & $9: 20$ & $1: 55$ \\
\hline $\begin{array}{l}\text { Specimen } \\
\text { at 53 C }\end{array}$ & Final (h: min) & $12: 40$ & $2: 45$ \\
\hline $\begin{array}{l}\text { Specimen at 2.5 } \\
\text { m/s wind }\end{array}$ & Initial (h: min) & $5: 10$ & $1: 30$ \\
& Final (h: min) & $7: 30$ & $1: 55$ \\
\hline & Final (h: $\min )$ & $5: 05$ & $2: 10$ \\
\hline
\end{tabular}

Both increased temperature and increased wind speed cause reductions in setting time, but the reductions are greater in the specimens with the retarder. Table 8 indicates the corresponding percentage reductions, i.e. as percentages of the setting times for the control conditions $\left(31^{\circ} \mathrm{C}\right.$ and no wind). This table also shows that the reductions for the specimens with retarder are greater for the wind effect than for the temperature effect; the reverse is true for the specimens without the retarder. The effect of wind is ambiguous however, because stiffening will probably be due more to drying than to hydration.

Table 8 - Percentage reductions in cement setting time 


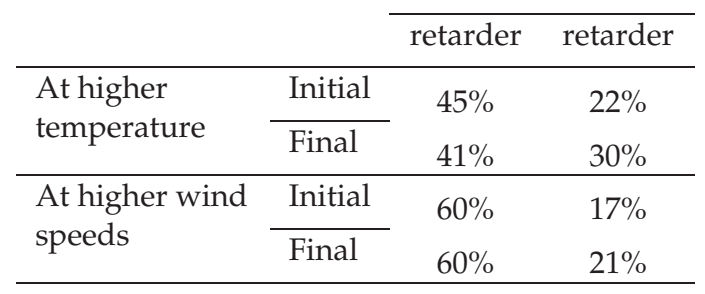

\subsection{Surface and interior quality}

One aspects of importance in this study is the question as to whether the surface quality of retarder overdosed concrete is better or poorer than the interior, because it is surface tests (such as rebound hammer tests) that are mainly used in the field to monitor the hardening of concrete with delayed setting. The results from our study are somewhat ambiguous in this regard. On the one hand, as depicted in Table 6, the rebound number strengths are less than the top core strengths for concrete with a retarder overdose, thus indicating that the interior strength is better than that reflected by surface tests. On the other hand, equivalent cube strength results from cores are progressively lower than the corresponding cube test results, as retarder dosages increase, especially beyond 3ND (Table 5 and Figure 1). This suggests that strength development in large sections with retarder overdosing is slower than indicated by small specimens. The cement setting time tests also indicate that in retarded concretes the surface, if subject to wind, will stiffen (and perhaps harden) quicker than the interior, although the setting of the latter too will be accelerated by higher temperatures. This question of surface versus interior quality is clearly one that merits further investigation. Where thin sections are concerned differences between the surface and interior are likely to be less.

\section{Conclusions}

The following main conclusions can be drawn, based on this investigation that used the retarder Pozzolith 300R, an admixture made to satisfy the ASTM Type B and D requirements.

1) An overdose of retarder up to 3 times the normal dosage can be easily accommodated in concrete practice, with concrete strength gain not being appreciably affected.

2) Concrete with retarder overdoses of up to even 6 times the normal dosage will eventually reach or even exceed their corresponding 28 day strengths.

3) Equivalent cube strength results from cores are progressively lower than the corresponding cube test results, as retarder dosages increase.

4) Reductions in cement setting time for the specimens with a retarder are greater for the effect of a $2.5 \mathrm{~m} / \mathrm{s}$ wind than for a temperature increase of $22^{\circ} \mathrm{C}$ above the ambient $31^{\circ} \mathrm{C}$.

5) The question as to whether the interior quality of retarder overdosed concretes is better or poorer than the surface quality could not be resolved unambiguously, and requires further investigation.

\section{References}

1) ASTM C494. Standard specification for chemical admixtures for concrete. Philadelphia: American Society for Testing Materials, Vol. 04.02; 1988.

2) Dodson VH. Concrete Admixtures. New York: Van Nostrand Reinhold; 1990

3) Ramachandran VS, Feldman RF, Beaudoin JJ. Concrete science: Treatise on current research. London: Heyden; 1981.

4) Dias WPS. Delayed setting of concrete in foundations of Sahanaya mental rehabilitation centre. Technical Report, University of Moratuwa, 2004. 
5) Dias WPS. Delayed setting of concrete transfer slab at 202 WA Silva Mawatha, Colombo 6. Technical Report, University of Moratuwa, May 2007.

6) BS 882: 1992. Specification for aggregate from natural resources for concrete. London: British Standards Institution; 1992.

7) ASTM C403. Time of setting of concrete mixtures by penetration resistance. Philadelphia: American Society for Testing Materials, Vol. 04.02; 1986.

8) BS 4550: Part 3: Section 3.6: 1978. Methods of testing cement: Test for setting time. London: British Standards Institution; 1978.

9) Dias WPS. Correlation of non-destructive test results with concrete strength. Engineer, Sri Lanka, March 1991, pp. 3-13. 